\title{
THE
}

\section{Feasibility of Delivering a Tailored Intervention for Advance Care Planning in Primary Care Practice}

\author{
Andrea L. Paiva \\ University of Rhode Island, apaiva@uri.edu \\ Colleen A. Redding \\ University of Rhode Island, credding@uri.edu \\ Lynne lannone \\ Maria Zenoni \\ John R. O'Leary
}

See next page for additional authors

Follow this and additional works at: https://digitalcommons.uri.edu/psy_facpubs

This is a pre-publication author manuscript of the final, published article.

Terms of Use

All rights reserved under copyright.

\section{Citation/Publisher Attribution}

Paiva, A., Redding, C. A., Iannone, L., Zenoni, M., O'Leary, J. R., \& Fried, T. R. (2020). Feasibility of Delivering a Tailored Intervention for Advance Care Planning in Primary Care Practice. Journal of the American Geriatrics Society, 67(9), 1917-1921. https://doi.org/10.1111/jgs.16035

Available at: https://doi.org/10.1111/jgs.16035 
Authors

Andrea L. Paiva, Colleen A. Redding, Lynne lannone, Maria Zenoni, John R. O'Leary, and Terri R. Fried

This article is available at DigitalCommons@URI: https://digitalcommons.uri.edu/psy_facpubs/88 
Published in final edited form as:

J Am Geriatr Soc. 2019 September ; 67(9): 1917-1921. doi:10.1111/jgs.16035.

\title{
Feasibility of Delivering a Tailored Intervention for Advance Care Planning in Primary Care Practice
}

\author{
Andrea Paiva, $\mathrm{PhD}^{1,2}$, Colleen A. Redding, $\mathrm{PhD}^{1,2}$, Lynne lannone, $\mathbf{M S}^{3,4}$, Maria Zenoni, \\ MS $^{5}$, John R. O'Leary, MA ${ }^{3,4}$, Terri R. Fried, MD ${ }^{4,5}$ \\ ${ }^{1}$ Cancer Prevention Research Center, College of Health Sciences, University of Rhode Island, \\ ${ }^{2}$ Psychology Department, College of Health Sciences, University of Rhode Island, ${ }^{3}$ Program on \\ Aging, Yale School of Medicine ${ }^{4}$ Department of Medicine, Yale School of Medicine ${ }^{5} \mathrm{Clinical}$ \\ Epidemiology Research Center, VA Connecticut Healthcare System
}

\begin{abstract}
Background/Objectives: To determine the feasibility of conducting a cluster randomized controlled trial (RCT) providing individualized feedback reports to increase ACP engagement in the primary care setting.

Design: Pilot cluster RCT

Setting: Two primary care practices selected for geographic co-location.

Participants: Adults age 255 .

Intervention: Brief assessment of readiness to engage in (stage of change for) three ACP behaviors (health care agent assignment, communication with agent about quality versus quantity of life, living will completion) generating an individualized feedback report, plus a stage-matched brochure.
\end{abstract}

Measures: Patient recruitment and retention, intervention delivery, baseline characteristics, stage of change movement.

Results: Recruitment rates differed by practice. Several baseline sociodemographic characteristics differed between the 38 intervention and 41 control participants, including employment status, education, and communication with health care agent. Feedback was successfully delivered to all intervention participants, and over $90 \%$ of participants completed a 2month follow- More intervention participants demonstrated progression in readiness than did control participants, without testing for statistical significance.

Corresponding author: Terri R. Fried, MD, CERC 240, VA Connecticut Healthcare System, 950 Campbell Avenue, West Haven, Connecticut, USA 06516. terri.fried@yale.edu.

Author Contributions:

TRF conceived and designed the study. All authors participated in the acquisition, analysis, and interpretation of data, drafting the paper or revising it critically, and provided final approval.

Conflict of Interest:

The authors have no conflicts. 
Conclusions: This pilot demonstrates opportunities and challenges of performing a clustered RCT in primary care practices. Differences in the two practice populations highlight the challenges of matching sites. There was a signal for behavior change in the intervention group.

\section{Keywords}

Advance care planning; behavior change; primary care

Advance care planning (ACP), the process by which individuals can plan for future difficult medical decisions and possible decisional incapacity, has been endorsed as the means by which patients can retain control over the care they receive at the end of life, and, to the extent possible, receive care consistent with their preferences. ${ }^{1}$ ACP is associated with improved caregiver outcomes. ${ }^{2,3}$ Having originated as the completion of advance directives (AD) including living wills and designation of health care surrogates, ACP is increasingly recognized as requiring the promotion of communication among patients, their surrogate decision-makers, and their clinicians. ${ }^{4} \mathrm{ACP}$ is underutilized, with a recent systematic review concluding that only approximately one-third of adults in the USA have completed ADs. ${ }^{5}$

Respecting Choices, the most extensively studied program for promoting participation in ACP, improves surrogates' knowledge of patients' preferences and reduces caregiver stress. 6,7 This intervention, consisting of facilitated discussions between patients and surrogates by moderators with specialized training, requires extensive resources for implementation. ${ }^{8}$ Several tools have been developed to guide patients through the process of ACP, including the Conversation Project ${ }^{9}$ and the PREPARE website, ${ }^{10}$ which increases ACP documentation. ${ }^{11,12}$

The STAMP (Sharing and Talking about My Preferences) program was designed to address the gap between intensive clinician-led and self-administered tools. Based on the Transtheoretical Model, ${ }^{13}$ it consists of a brief assessment of readiness to engage in an interrelated set of ACP activities and the attitudes, beliefs, and practices that influence readiness generating an individualized feedback report. The assessment and feedback is performed in conjunction with an ambulatory office visit to facilitate the review of the written materials and to encourage individuals to bring questions about their particular health conditions to their clinician.

We performed a pilot study of the STAMP program with the primary objective of determining the feasibility of enrolling and retaining individuals from primary care practices. As the first study to evaluate the STAMP program, it included a secondary objective of providing preliminary data regarding associations with readiness to engage in ACP.

\section{METHODS}

\section{Participants}

We selected two primary care practices belonging to the same not-for-profit multispecialty medical foundation with shared hospital and academic affiliations and leadership but no shared clinical staff, located in the same office building, with the original plan to have one 
serve as the intervention and the other as the control site. Site rather than patient was chosen as the level of assignment in order to minimize the likelihood of contamination. Daily lists were generated of patients meeting inclusion criteria: well-visit appointment and age 55 years or older. These lists were reviewed with office staff to remove the names of individuals with exclusion criteria: non-English speaking, severe vision or hearing impairment, cognitive impairment, physician discretion. The goal was 50 participants in each group within in a prespecified time frame in order to establish a feasible recruitment rate for a larger study. The protocol was approved by the Bridgeport Hospital IRB, and all participants completed written informed consent.

\section{Recruitment}

Medical assistants provided potentially eligible patients with an information sheet to read while waiting for their physician. Physicians were encouraged to acknowledge the sheet when they saw their patients and endorse study participation. Willing participants were brought at the end of their appointment to a research assistant, who screened the participant for the exclusion criterion of having completed the three ACP activities described below. Eligible participants completed a process of written informed consent. No compensation was provided to practices or participants.

\section{Study Arms}

Research assistants administered the STAMP assessment via a laptop computer or tablet. The assessment assesses readiness to engage in three ACP activities: designation of a health care agent, communication regarding views on quality versus quantity of life, and completion of a living will. Participants were characterized as being in one of four stages of change for each behavior: precontemplation (no knowledge of or not being ready to engage in the activity), contemplation (thinking about engaging in the next six months), preparation (planning on engaging in the next four weeks), and action/maintenance (completed the activity). ${ }^{14}$ Participants were asked about pros and cons of and values and medical beliefs regarding engagement, and processes of change. ${ }^{15}$ The assessment generates a personalized feedback report delivered to the participant using a portable printer. The report begins with a common introduction defining advance care planning and then provides stage-based feedback for the ACP activities. For patients in early stages of behavior change, the feedback focuses on changing attitudes, a prerequisite to changing behavior. They also received a brief brochure focusing on strategies to overcome common attitudinal barriers to ACP engagement, including two stories adapted from prior research that illustrated the benefits of ACP engagement. For individuals in later stages, the feedback provides specific next-steps to accomplish the ACP activities. They also received a longer brochure providing strategies for completing each activity. ${ }^{16}$

Participants in the control group completed the assessment but did not receive feedback materials. In order to decrease the likelihood of assessment alone prompting behavior change, they finished with questions about readiness to engage in exercise. 


\section{Measures and Analysis}

All participants were asked about sociodemographic and health status. The STAMP assessment was repeated at a two-month phone call. To assess feasibility, we tracked the flow of patients through the study. The research staff also recorded their observations regarding recruitment.

Preliminary data regarding movement in stage of change were examined descriptively (no significance testing) by characterizing the number and proportion of participants not in action/maintenance for each of the three activities at baseline who: a) progressed to or regressed from action; b) had any progression or regression.

\section{RESULTS}

\section{Participant flow}

Large numbers of patients were screened in order to recruit the study population (Figure 1). There were notable differences between the two practices (Intervention Site 1 and Control Site 2) in participant flow. Over a two-month recruitment period, nearly twice the number of patients in the control practice refused participation (Control Site 2), while a substantially smaller number had already completed the three ACP activities. Sizeable numbers of patients in both practices were never seen by the research team. The research team observed a lower level of enthusiasm for the study among physicians in the control practice. These physicians were less likely than physicians in the intervention practice to let research assistants know they were recommending the study to their patients and to walk the patient to the research assistant. Because of the slower rate of recruitment in the control practice, the research team completed recruitment of the control group from the initially designated intervention practice after the intervention group had been recruited (Control Site 1). Reflecting the faster rate of recruitment in this practice, the additional control patients were identified in 3 weeks. However, a total of 79, rather than the target sample of 100 were enrolled in the allotted time period for recruitment. The baseline assessment was successfully completed with all participants, and the intervention participants received their feedback reports and brochures. The research team successfully completed 73/79 two-month telephone follow-ups.

\section{Participant characteristics and outcomes}

Baseline characteristics of participants in the intervention group and in the control groups separated by recruitment site are provided in Table 1 . The 19 participants recruited for the control group from Site 1 were less likely to be married, to have a high school education, and to be employed full time than were participants recruited from the same site for the intervention group, and more closely resembled the participants recruited from Site 2 regarding these characteristics.

The intervention and control groups were fairly well balanced at baseline in terms of living will completion and health care agent designation. A greater proportion of individuals in the intervention group had communicated with loved ones regarding quality versus quantity of life than in the control group. With overall small numbers, there was a pattern of larger 
proportions of participants in the intervention group progressing to action for each of the behaviors (Table 2). Larger proportions also had any progression in their stage of change for completing a living will and designating a health care agent. Across all behaviors, small proportions in both groups had regression without a consistent pattern.

\section{DISCUSSION}

This pilot study examined the feasibility of an intervention to promote ACP participation by bridging a gap between intensive clinician-led programs and self-administered tools. The results highlight both the opportunities and challenges in efforts to integrate ACP into routine health care by delivering the intervention in primary care practices. Recruitment fell short of its target. With assignment to study arm originally made at the level of the practice, recruitment was much more successful in one practice versus the second. Imbalances in sociodemographic characteristics and ACP engagement at baseline existed, even though about one-half of controls were recruited from the originally designated intervention site. Once participants were enrolled, they were successfully provided with intervention materials, and virtually all completed a follow-up assessment. With overall small numbers and no significance testing, there was a consistent signal of greater behavior change in the intervention group. Larger proportions of participants in the intervention group reported completing each of the ACP behaviors at follow-up and had any readiness progression for two of the behaviors.

The experience with recruitment provided important insights for the conduct of studies using cluster randomization at the practice level. We selected practices in the same building to match the patient populations according to race/ethnicity and sociodemographic status. Because of small numbers, it is difficult to draw conclusions about the comparability of the intervention and control groups. However, the two sites clearly had important differences between them, as evidenced by the proportions of patients who were not eligible for participation in the study because they had completed all ACP activities. These findings highlight the challenges of matching practices. The research team also encountered differences in the willingness of the clinicians to endorse the study and encourage patient participation. In addition to affecting the efficiency of recruitment, this may also affect the characteristics of the patients who are referred for participation, further complicating the attempt to match participants when they are not the unit of randomization.

The ability to deliver printed tailored materials generated on site in the clinical setting was an important aspect of demonstrating feasibility. While there is rapid growth in the use of electronic media to deliver behavioral interventions, the optimal format remains unclear. ${ }^{17}$ Moreover, a substantial proportion of older persons do not use the Internet, ${ }^{18}$ making the availability of print materials particularly important in this population. The high retention rate in both the intervention and control groups provides further evidence of the acceptability of the STAMP assessment. ${ }^{16}$

Because ipsative feedback informing individuals about their own behavior change over time is a key component of behavior change, ${ }^{19}$ the intervention is designed to be administered repeatedly over time. Given the single exposure to the intervention, the small number of 
participants, and the imbalance in ACP participation at baseline, we examined changes in readiness to engage in ACP descriptively for preliminary signals of effect. Interpreted in this way, there was a consistent signal of intervention group participants demonstrating greater changes in readiness. An alternative explanation is that, because more participants in the intervention group had communicated with their loved ones about quality versus quantity of life than in the control group, they were more "primed" for change. However, a prior crosssectional observational study did not demonstrate that patients in later stages of change for one ACP activity were more likely to be in later stages of other activities. ${ }^{14}$ While there was a small amount of backward movement in both groups, it did not appear to be differential. Backward movement may reflect either an improved understanding of the ACP behaviors provided by the assessment or a true change in attitude.

By involving only a single pair of clinical practices, it provided limited experience with recruitment, and the small numbers made it challenging to evaluate the adequacy of the matching. Nonetheless, it demonstrates the feasibility of an intervention delivered in clinical practices to provide print tailored feedback materials with the goal of increasing engagement in ACP.

\section{ACKNOWLEDGEMENTS}

Funding sources: National Institute of Nursing Research (R01 NR016007) and the Claude D. Pepper Older Americans Independence Center at Yale University School of Medicine (P30AG21342 National Institute on Aging). This work was supported with resources and the use of facilities at the VA Connecticut Healthcare System. The contents do not represent the views of the U.S. Department of Veterans Affairs or the United States Government.

Sponsor's Role: The sponsor had no role in the design, methods, analysis, or preparation of the paper.

\section{REFERENCES}

1. Institute of Medicine. Dying in America: Improving and honoring individual preferences near the end of life. Washington, DC: The National Academies Press; 2014.

2. Wright AA, Zhang B, Ray A, et al. Associations between end-of-life discussions, patient mental health, medical care near death, and caregiver bereavement adjustment. JAMA 2008;300:1665-73. [PubMed: 18840840]

3. Chiarchiaro J, Buddadhumaruk P, Arnold RM, et al. Prior advance care planning is associated with less decisional conflict among surrogates for critically ill patients. Ann Am Thorac Soc 2015;12:1528-33. [PubMed: 26240996]

4. Sudore RL, Fried TR. Redefining the "planning" in advance care planning: preparing for end-of-life decision making. Ann Intern Med 2010;153:256-61. [PubMed: 20713793]

5. Yadav KN, Gabler NB, Cooney E, et al. Approximately one in three US adults completes any type of advance directive for end-of-life care. Health Aff (Millwood) 2017;36:1244-51. [PubMed: 28679811]

6. Detering KM, Hancock AD, Reade MC, et al. The impact of advance care planning on end of life care in elderly patients: randomised controlled trial. BMJ 2010;340:c1345. [PubMed: 20332506]

7. Kirchhoff KT, Hammes BJ, Kehl KA, et al. Effect of a disease-specific planning intervention on surrogate understanding of patient goals for future medical treatment. J Am Geriatr Soc 2010;58:1233-40. [PubMed: 20649686]

8. Wilson KS, Kottke TE, Schettle S. Honoring Choices Minnesota: Preliminary data from a community-wide advance care planning model. J Am Geriatr Soc 2014;62:2420-5. [PubMed: 25516036]

9. The Conversation Project. (Accessed July 7, 2016, at http://theconversationproject.org/.) 
10. Sudore RL, Knight SJ, McMahan RD, et al. A novel website to prepare diverse older adults for decision making and advance care planning: A pilot study. J Pain Symptom Manage 2014;47:67486. [PubMed: 23972574]

11. Sudore R, Le G, McMahon R, et al. The advance care planning PREPARE study among older Veterans with serious and chronic illness: study protocol for a randomized controlled trial. Trials 2015;16:570. [PubMed: 26654250]

12. Sudore RL, Boscardin J, Feuz MA, et al. Effect of the PREPARE website vs an easy-to-read advance directive on advance care planning documentation and engagement among veterans: A randomized clinical trial. JAMA Intern Med 2017;177:1102-9. [PubMed: 28520838]

13. Prochaska JO, Redding CA, Evers KE. The Transtheoretical Model and Stages of Change In: Glanz K, Rimer BK, Viswanath KV, eds. Health Behavior and Health Education: Theory, Research, and Practice 4th edition. San Francisco: Jossey-Bass; 2008:170-222.

14. Fried TR, Redding CA, Robbins ML, et al. Stages of change for the component behaviors of advance care planning. J Am Geriatr Soc 2010;58:2329-36. [PubMed: 21143441]

15. Fried TR, Redding CA, Robbins ML, et al. Promoting advance care planning as health behavior change: Development of scales to assess Decisional Balance, Medical and Religious Beliefs, and Processes of Change. Patient Educ Couns 2012;86:25-32. [PubMed: 21741194]

16. Fried TR, Redding CA, Robbins ML, et al. Development of personalized health messages to promote engagement in advance care planning. J Am Geriatr Soc 2016;64:359-64. [PubMed: 26804791]

17. Marshall AL, Leslie ER, Bauman AE, et al. Print versus website physical activity programs: A randomized trial. Am J Prev Med 2003;25:88-94. [PubMed: 12880874]

18. Cashen MS, Dykes P, Gerber B. eHealth technology and Internet resources: barriers for vulnerable populations. Journal of Cardiovasc Nurs 2004;19:209-16.

19. Prochaska JO. Decision making in the transtheoretical model of behavior change. Med Decis Making 2008;28:845-9. [PubMed: 19015286] 

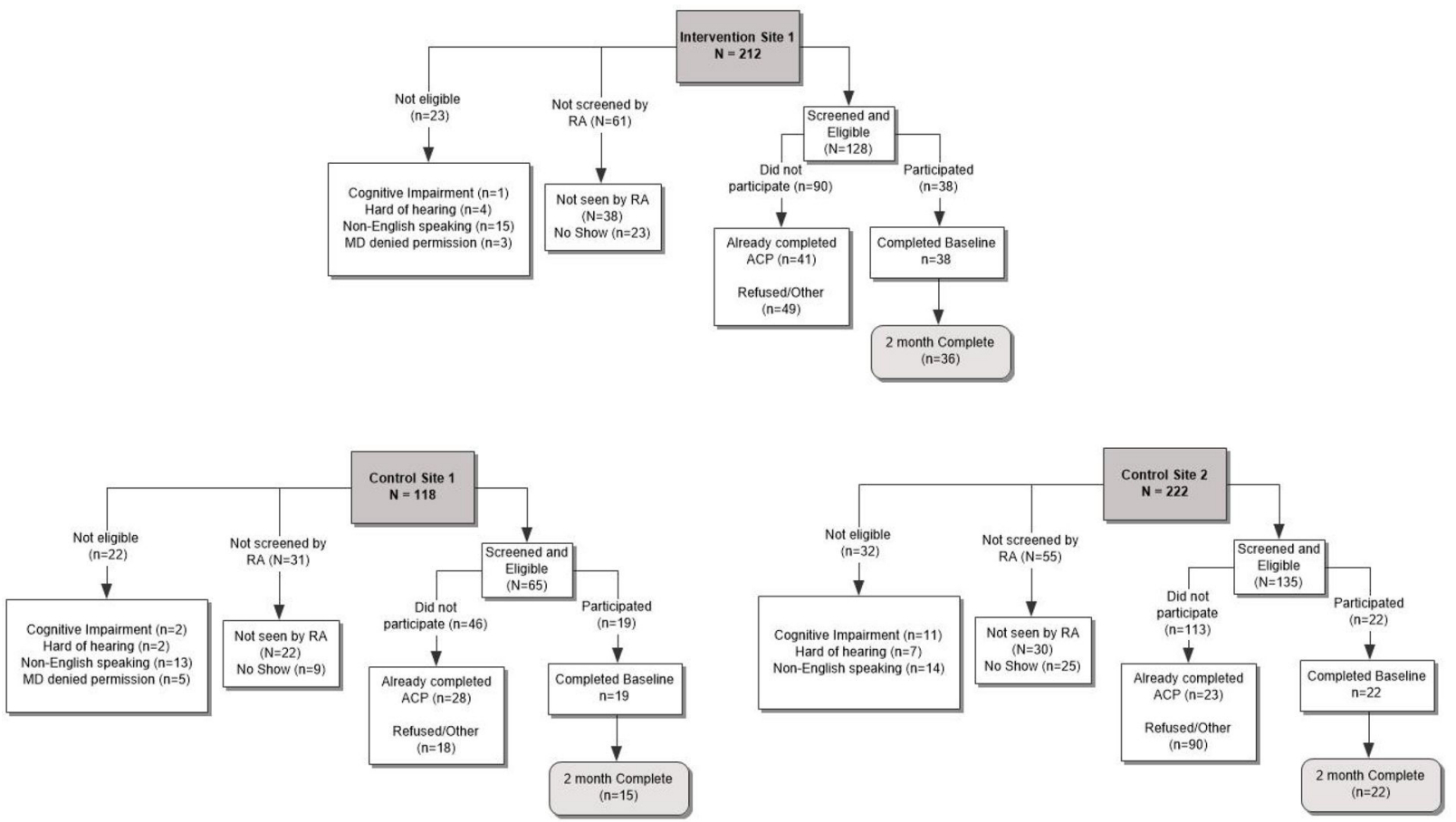

Figure 1:

Flow diagram of participant recruitment. Intervention Site 1 and Control Site 1 represent the same clinical practice, while Control Site 2 represents a second clinical practice. RA = Research Assistant 
Table 1:

Participant characteristics according to practice site

\begin{tabular}{|l|l|l|l|}
\hline & Intervention Site 1 $^{*}(\mathbf{n}=\mathbf{3 8})$ & ${\text { Control Site } \mathbf{1}^{*}(\mathbf{n}=\mathbf{1 9})}$ & Control Site 2 (n=22) \\
\hline Characteristic & $\mathrm{n}(\%)$ & $\mathrm{n}(\%)$ & $\mathrm{n}(\%)$ \\
\hline Non-white race & $6(16)$ & $2(11)$ & $3(14)$ \\
\hline Women & $24(63)$ & $10(53)$ & $14(64)$ \\
\hline Education $<=12^{\text {th }}$ grade & $2(5)$ & $8(42)$ & $8(36)$ \\
\hline Money left over & $25(66)$ & $11(58)$ & $17(77)$ \\
\hline Married & $27(71)$ & $9(47)$ & $13(59)$ \\
\hline Employed full-time & $16(42)$ & $3(16)$ & $4(18)$ \\
\hline Excellent self-rated health & $9(24)$ & $2(11)$ & $4(18)$ \\
\hline Best possible QOL & $17(45)$ & $7(37)$ & $9(41)$ \\
\hline Living will A/M & $8(21)$ & $5(26)$ & $5(23)$ \\
\hline Health care agent A/M & $10(26)$ & $6(32)$ & $6(27)$ \\
\hline Communication A/M & $24(63)$ & $10(53)$ & $8(36)$ \\
\hline
\end{tabular}

$\mathrm{QOL}=$ quality of life, $\mathrm{A} / \mathrm{M}=$ action/maintenance

*

Intervention Site 1 and Control Site 1 refer to the same practice 
Table 2:

Two Month Stage Progression/Regression for each of three ACP behaviors

\begin{tabular}{|l|l|l|}
\hline & Intervention & Control \\
\hline Progression to action & $\mathrm{n} / \mathrm{N}(\%)$ & $\mathrm{n} / \mathrm{N}(\%)$ \\
\hline Living will & $2 / 29(7)$ & $1 / 27(4)$ \\
\hline Health care agent & $2 / 27(7)$ & $0 / 25(0)$ \\
\hline Communication quality versus quantity & $6 / 13(46)$ & $8 / 21(38)$ \\
\hline Any progress from an earlier to a later stage & & \\
\hline Living will & $9 / 29(31)$ & $6 / 27(22)$ \\
\hline Health care agent & $7 / 27(26)$ & $4 / 25(16)$ \\
\hline Communication quality versus quantity & $7 / 13(54)$ & $12 / 21(57)$ \\
\hline Regression from action & & \\
\hline Living will & $0 / 7(0)$ & $1 / 10(10)$ \\
\hline Health care agent & $0 / 9(0)$ & $0 / 12(0)$ \\
\hline Communication quality versus quantity & $4 / 23(17)$ & $4 / 16(25)$ \\
\hline Any regression from a later to an earlier stage & & \\
\hline Living will & $5 / 36(14)$ & $7 / 37(19)$ \\
\hline Health care agent & $7 / 36(19)$ & $4 / 37(11)$ \\
\hline Communication quality versus quantity & $6 / 36(17)$ & $6 / 37(16)$ \\
\hline
\end{tabular}

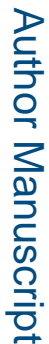

